\title{
Anti-TIM3 Monoclonal Antibody LY3321367
}

National Cancer Institute

\section{Source}

National Cancer Institute. Anti-TIM3 Monoclonal Antibody LY3321367. NCI Thesaurus.

Code $C 137820$

A monoclonal antibody against the inhibitory $\mathrm{T}$-cell receptor $\mathrm{T}$-cell immunog lobulin and mucin domain-containing protein 3 (TIM-3; TIM3; hepatitis A virus cellular receptor 2; HAVCR2), with potential immune checkpoint inhibitory and antineoplastic activities. Upon administration, the anti-TIM-3 monoclonal antibody LY3321367 binds to TIM-3 expressed on certain T-cells, including tumor infiltrating lymphocytes (TILs). This abrogates T-cell inhibition, activates antigen-specific T-lymphocytes and enhances cytotoxic T-cell-mediated tumor cell lysis, which results in a reduction in tumor growth. TIM-3, a transmembrane protein and immune checkpoint receptor, is associated with tumor-mediated immune suppression. 